\title{
Assessing airflow rates of a naturally ventilated test facility using a fast and simple algorithm supported by local air velocity measurements
}

\author{
G. De Vogeleer ${ }^{\text {a, b }}$, P. Van Overbeke ${ }^{\text {a, b }}$, E. Brusselman ${ }^{\text {a }}$, L.B. Mendes ${ }^{\text {a, }}{ }^{1}$, J.G. Pieters ${ }^{\text {b }}$, \\ P. Demeyer ${ }^{\text {a, * }}$
}

a Technology \& Food Unit, Institute for Agricultural and Fisheries Research (ILVO), B. Van Gansberghelaan 115, 9820 Merelbeke, Belgium

${ }^{\mathrm{b}}$ Department of Biosystems Engineering, Ghent University, Coupure Links 653, 9000 Ghent, Belgium

\section{A R T I C L E I N F O}

\section{Article history:}

Received 22 February 2016

Received in revised form

15 April 2016

Accepted 3 May 2016

Available online 7 May 2016

\section{Keywords:}

Natural ventilation

Ultrasonic anemometry

Animal houses

Airflow rates

\begin{abstract}
A B S T R A C T
The high spatial and temporal variations of airflow patterns in ventilation openings of naturally ventilated animal houses make it difficult to accurately measure the airflow rate. This paper focusses on the development of a fast assessment technique for the airflow rate of a naturally ventilated test facility through the combination of a linear algorithm and local air velocity measurements. This assessment technique was validated against detailed measurement results obtained by the measuring method of Van Overbeke et al. (2015) as a reference.

The total air velocity $|\bar{U}|$, the normal $|\bar{Y}|$ and tangential velocity component $|\bar{X}|$ and the velocity vector $\bar{U}$ measured at the meteomast were chosen as input variables for the linear algorithms. The airflow rates were split in a group where only uni-directional flows occurred at vent level (no opposite directions of $|\bar{Y}|$ present in the airflow pattern of the opening), and a group where bi-directional flows occurred (the air goes simultaneously in and out of the opening). For airflow rates with uni-directional flows the input variables $\bar{U}$ and $|\bar{Y}|$ yielded the most accurate results. For this reason, it was suggested to use the $|\bar{Y}|$ instead of $|\bar{U}|$ in ASHRAE's formula of $Q=E \times A \times|\bar{U}|$.

For bi-directional flows a multiple linear model was suggested where input variable $\bar{U}$ gave the best results to assess the airflow rate.
\end{abstract}

() 2016 Elsevier Ltd. All rights reserved.

\section{Contents}

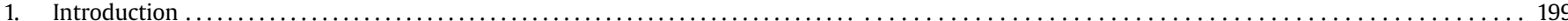

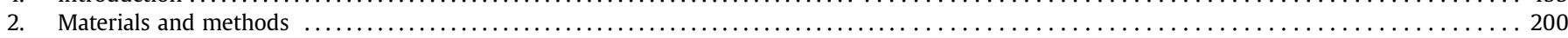

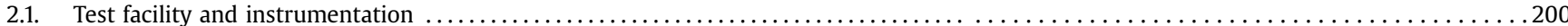

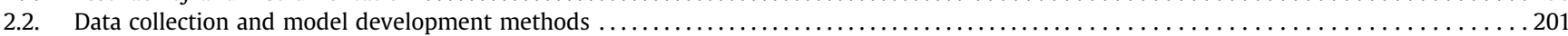

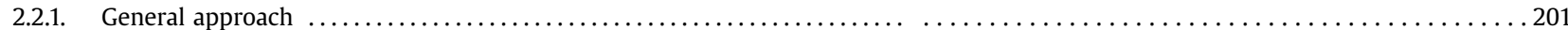

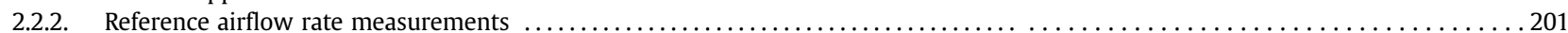

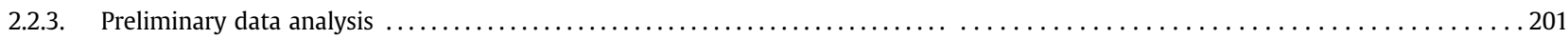

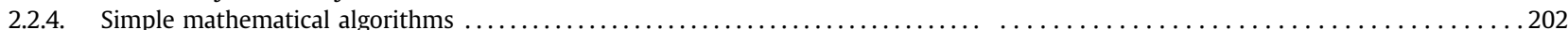

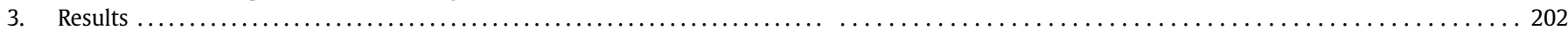

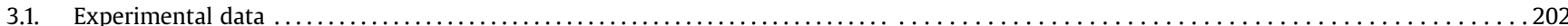

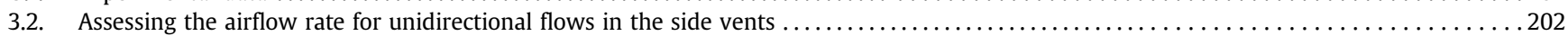

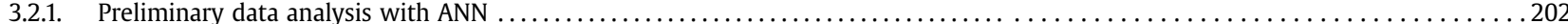

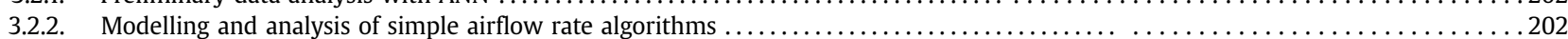

\footnotetext{
* Corresponding author.

E-mail address: peter.demeyer@ilvo.vlaanderen.be (P. Demeyer).

1 Present address: Ecosystems Services and Management/Mitigation of Air Pollution and Greenhouse Gases, International Institute for Applied Systems Analysis, Schlossplatz 1, A-2361 Laxenburg, Austria.
} 


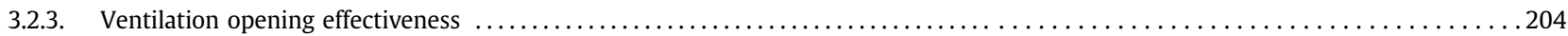

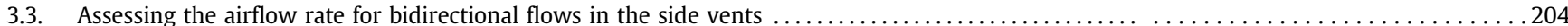

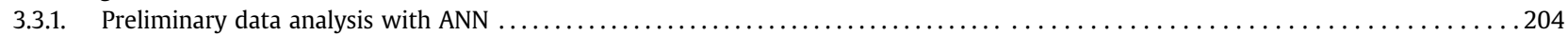

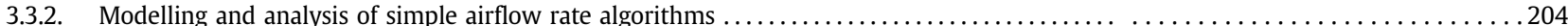

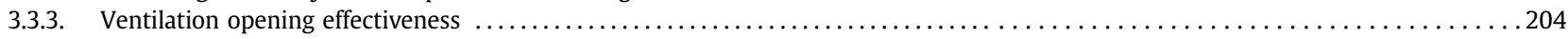

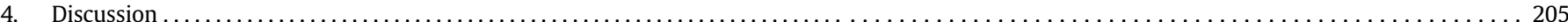

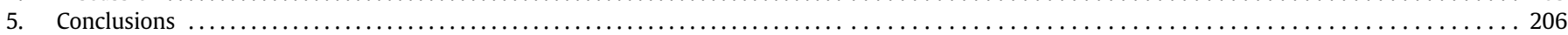

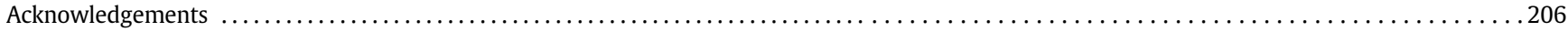

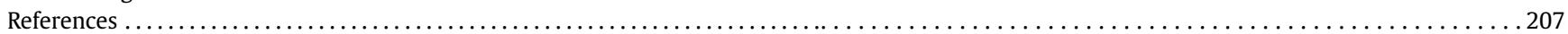

\begin{tabular}{|c|c|c|c|}
\hline \multicolumn{2}{|c|}{ Nomenclature } & \multirow{2}{*}{$\begin{array}{l}\text { Quni } \\
\text { RR }\end{array}$} & \multirow{2}{*}{$\begin{array}{l}\text { airflow rate with uni-directional flow in the side vents } \\
\left(\mathrm{m}^{3} / \mathrm{h}\right) \\
\text { reference results }\end{array}$} \\
\hline$A$ & surface area $\left(\mathrm{m}^{2}\right)$ & & \\
\hline$A p$ & partial surface area $\left(\mathrm{m}^{2}\right)$ & SE & south east \\
\hline ANN & Artificial Neural Networks & SD & standard deviation \\
\hline$\beta_{0}$ & regression coefficient Bland Altman plot & SW & south west \\
\hline$\beta_{1}$ & intercept Bland Altman plot $\left(\mathrm{m}^{3} / \mathrm{h}\right)$ & $\bar{U}$ & velocity vector (m/s) \\
\hline$C_{D}$ & still-air discharge component (dimensionless) & $|\bar{U}|$ & total air velocity $(\mathrm{m} / \mathrm{s})$ \\
\hline E & opening effectiveness (dimensionless) & $V$ & reference velocity $(\mathrm{m} / \mathrm{s})$ \\
\hline MR & model results & $|\bar{X}|$ & tangiental air velocity component $(\mathrm{m} / \mathrm{s})$ \\
\hline $\begin{array}{l}\text { NE } \\
\text { NW }\end{array}$ & $\begin{array}{l}\text { north east } \\
\text { north west }\end{array}$ & $|\bar{Y}|$ & perpendicular air velocity component $(\mathrm{m} / \mathrm{s})$ \\
\hline$\Delta P$ & pressure difference across the opening (Pa) & $\rho$ & air density $\left(\mathrm{kg} / \mathrm{m}^{3}\right)$ \\
\hline$Q_{b i}$ & $\begin{array}{l}\text { airflow rate with bi-directional flow in the side vents } \\
\left(\mathrm{m}^{3} / \mathrm{h}\right)\end{array}$ & & \\
\hline
\end{tabular}

\section{Introduction}

An accurate assessment of ventilation rates of animal houses is important with regard to, among others, the quantification of the related emissions. The importance of accurate measurements of ammonia emissions from naturally ventilated animal houses has risen since the increasing awareness of its major impact on the environment [2] and its consequences as e.g. eutrophication by deposition on the soil or in the water.

However, measuring ventilation rates in commercial animal houses is difficult in practice, due to significant uncertainties in measurements [3].

Emissions from mechanically ventilated animal houses, as commonly used for pig and poultry production in Western Europe, can be measured and calculated by multiplying the differences in ammonia concentrations at the inlet and the outlet with the corresponding ventilation rates [4]. A similar straightforward emission measurement procedure is less evident in naturally ventilated stables and in particular for dairy stables with large openings, because of the strong dependency of the emissions on weather conditions and building geometry. Therefore, significant spatial and temporal variations of the air velocity and of $\mathrm{NH}_{3}$ concentrations occur in the ventilation openings of the stables. Errors in emissions measurements are often due to the complexity of the airflow rate measurements [5-8]. Currently there is no standardized reference method available for measuring the ventilation rate in naturally ventilated animal housing $[7,9,10]$.

Van Overbeke et al. Ref. [1] developed and validated an accurate measuring method for the airflow rate of a naturally ventilated test facility with continuous direct velocity measurements using moving sensors (more details are given in §2.3.2). However, simplification is still necessary to achieve a more practical, time-reduced, low-cost and yet sufficiently accurate method. Combining modelling techniques with local air velocity measurements could be of interest to develop such a method $[7,9,11]$. This with the aim to simplify and speed up the assessment of the ventilation rate and to result in real time determination of the ventilation rate. With this respect, the method of Van Overbeke et al. Ref. [1] can serve as an excellent starting point since it provides detailed information on the velocity profiles in the vents.

The conventional envelope model that describes how the air enters and leaves a building, is the Bernouilli equation as a simplification of the Navier-Stokes equations. This so-called 'orifice equation' [1] is the most general relation describing the airflow rate through large intentional openings [12-15].

$\boldsymbol{Q}=\boldsymbol{C}_{D} \times \boldsymbol{A} \times \sqrt{\frac{2 \boldsymbol{x}|\Delta \boldsymbol{P}|}{\rho}}$

Where

$Q=$ Airflow rate $\left(\mathrm{m}^{3} / \mathrm{s}\right)$

$C_{D}=$ Still-air discharge component (dimensionless)

$A=$ Surface area of the opening $\left(\mathrm{m}^{2}\right)$

$\Delta P=$ Pressure difference across the opening $(\mathrm{Pa})$

$\rho$ Air density $\left(\mathrm{kg} / \mathrm{m}^{3}\right)$

This equation applies a still-air discharge coefficient for a typical opening but it fails for large openings as the main assumptions are not fulfilled (e.g. pressure and velocity distributions are not constant in the opening [16]) and changes in weather conditions can cause unsteadiness for measuring or estimating the parameters in the formula $[17,18]$. On top of these difficulties, very large openings (as typically found in dairy cow houses) would make it even more challenging to sample air volumes using the orifice equation due to 
the increased possibility of bi-directional flows $\left(Q_{b i}\right)$ in the openings where opposite directions of air velocities normal to the opening are present. This possibility for bi-directionality makes it also difficult to couple (ammonia) concentration measurements to velocity measurements to obtain emission values. Models for airflow rates with uni-directional flows $\left(Q_{u n i}\right)$ in vent openings give less accurate results when applied to bi-directional flows [9,13]. Also, measurement methods as e.g. tracer gas tests commonly used in mechanically [19] and naturally ventilated constructions [20-23], perform poorly in accuracy and precision under naturally ventilated circumstances $[9,13]$ due to variations in air and concentration.

Etheridge Ref. [13] states the airflow rate $\left(Q_{u n i}\right)$ for very large openings in a formula [2] in non-dimensional terms.

$\frac{Q}{A \times V}=\mathrm{f}(\varnothing)$

Where.

$\mathrm{V}$ reference velocity $(\mathrm{m} / \mathrm{s})$

$f=$ wind direction as a function of e.g. the surroundings, the shape of the envelope.

ASHRAE Ref. [24] suggests a similar practical formula [3] including the opening effectiveness.

$Q=E \times A \times V$

$E=$ the opening effectiveness of the ventilation opening (dimensionless)

$\mathrm{V}=$ reference velocity $(\mathrm{m} / \mathrm{s})$

Different values for $E$ are given depending on the wind incidence angle to the opening. For perpendicular winds it varies between 0.5 and 0.6 and for winds diagonal to the ventilation opening between 0.25 and 0.35 [24].

Many references were found in field measurements presenting linear fits between the airflow rate and the total velocity for greenhouses [25], between the airflow rate and perpendicular velocity component for dairy stables [26] and multi-zone test building [27]. These references show a considerable amount of information has been found in the peer reviewed literature assessing natural ventilation with simple algorithms, but it is not always clear which input variables result in the most accurately modelled airflow rates, or which algorithm to use for airflow rates with bi-directional flows. Especially there is little information to be found in the literature body on the accuracy of the respective proposed models. Of course this is not unexpected since the lack of a reference method for airflow rate measurements. In order to estimate the accuracy of a model, some studies [28,29] base the reference airflow rate on pressure differences in the opening, but pressure is highly fluctuating at large openings while it cannot be applied to the formula of $Q_{u n i}$. When direct measurements are done, single measurements are mostly assumed to represent the mean velocity for a large surface area in the opening, usually with no prior calibrating of the single velocity measurement to the mean velocity of the represented area. For these experiments without calibration, it is possible to calculate the precision of the method used but not the accuracy of the method. Because the method of Van Overbeke et al. Ref. [1] scans the surface area with an ultrasonic anemometer moving step-by-step in the opening, it creates the opportunity to define a better estimation of the real airflow rates and as thus the accuracy and precision of a simplified method where limited velocity measurements are used.

The objective of this paper was to develop a fast, accurate and simple to use airflow rate assessment technique for a naturally ventilated test facility combining a fast algorithm with a limited number of local air velocity measurements collected on a meteomast. The assessment technique is tested for airflow rates of both uni- or bi-directional flows occurring in the side opening evaluated to the commonly used formula of ASHRAE to calculate the airflow rate. Artificial Neural Networks (ANN) were applied to evaluate the input variables before applying linear algorithms in order to find existing correlations. The algorithms were validated by comparing to detailed airflow rates obtained by the measuring method of Van Overbeke et al. [1,30,31] as a reference.

\section{Materials and methods}

\subsection{Test facility and instrumentation}

The test facility was situated on a site of the Institute for Agricultural and Fisheries Research in Merelbeke, Belgium $\left(+50^{\circ} 58^{\prime}\right.$ $38.56^{\prime \prime} \mathrm{N},+3^{\circ} 46^{\prime} 45.68^{\prime \prime} \mathrm{E}$; A on Fig. 1). The building was located in a rural area and was oriented such that the side openings faced NE and SW, the latter being the dominant wind direction in Flanders.

The test facility represented a section of a naturally ventilated pig house as commonly found in Flanders (Belgium). The internal dimensions of the test facility were $12.0 \mathrm{~m}$ length, $5.4 \mathrm{~m}$ width and $4.9 \mathrm{~m}$ ridge height. Its internal volume was $251 \mathrm{~m}^{3}$ (Fig. 2). The two opposite concrete sidewalls had a ventilation opening of $4.5 \mathrm{~m}$ by $0.5 \mathrm{~m}$ and a depth of $0.2 \mathrm{~m}$ but were adjusted with metal plates to $3.0 \mathrm{~m}$. The ridge vent was $4.0 \mathrm{~m}$ by $0.35 \mathrm{~m}$ and could be closed and sealed when desired. A door and a gate were present in the test facility, though always kept closed during the experiments.

A meteomast equipped with a 2D ultrasonic anemometer (Thies ${ }^{\circledR}$, Göttingen, Germany) was installed to measure the wind velocity components (tangential component $|\bar{X}|$ - and normal component $|\bar{Y}|$ to the ventilation opening), wind direction and temperature with a frequency of $1 \mathrm{~Hz}$, at a standard height of $10 \mathrm{~m}$ above field level ( $5 \mathrm{~m}$ above the top of the test facility). In the test facility, a total of eight 2D and two 3D ultrasonic sensors (Thies ${ }^{\circledR}$, Göttingen, Germany) were installed. Each of the two side openings was equipped with a 3D ultrasonic sensor installed on a 2D-linear guiding system (Fig. 2), that transported the sensor to pre-set

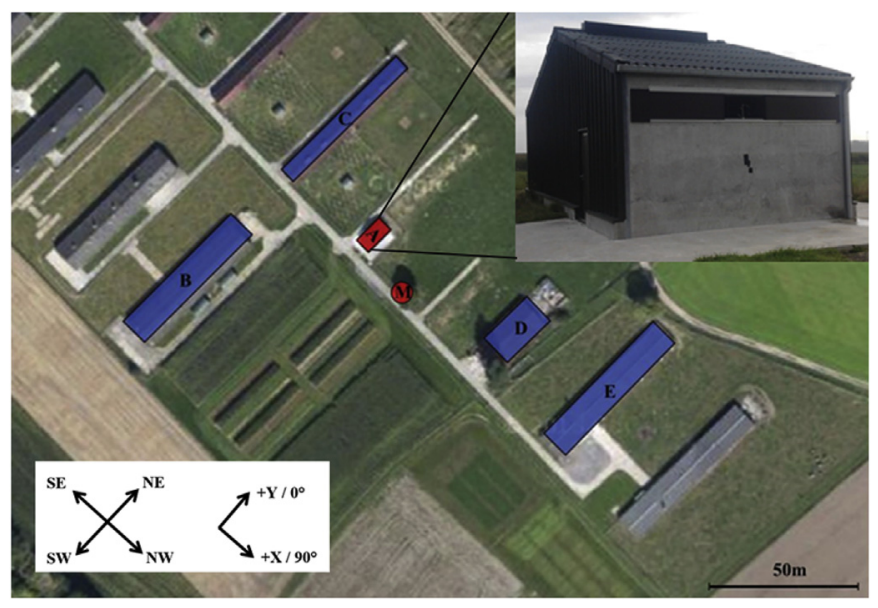

Fig. 1. Site and building of the experimental set-up. The surrounding buildings were located at a distance of $50 \mathrm{~m}$ from the test facility. (A) test facility (B-C-D-E) neighbouring buildings $(\mathrm{M})$ meteomast. 


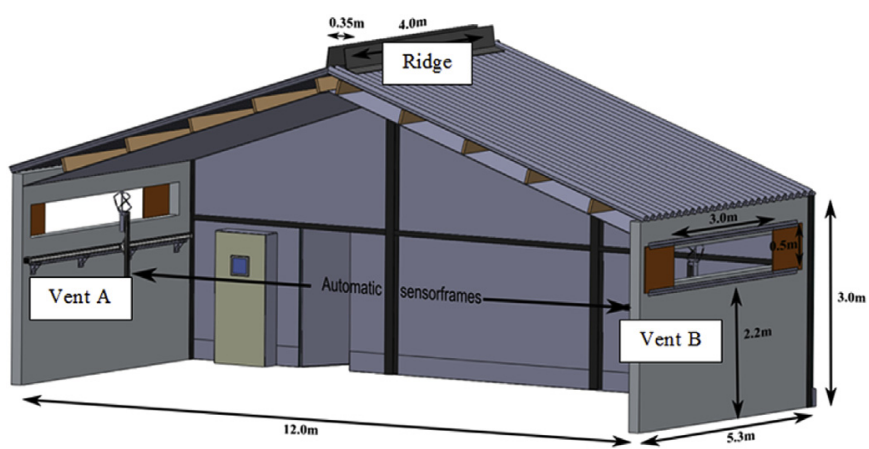

Fig. 2. A 3D sketch of the test facility at the Institute for Agricultural and Fisheries Research in Merelbeke.

places across the window openings where air velocities were automatically scanned following the sampling strategy developed by Van Overbeke et al. Ref. [1]. The ridge vent was equipped with eight 2D ultrasonic sensors equally distributed along the opening (one sensor malfunctioned during the experiment). Velocity and temperature were measured at a frequency of $50 \mathrm{~Hz}$ and $33 \mathrm{~Hz}$ for the 2DS and 3DS, respectively, and stored as 1s averages in a central logger (dataTaker ${ }^{\circledR}$ DT85M, Australia) via a serial interface (RS422)".

The measurement system described above was activated for continuous monitoring, day and night over several months (December 2014 through March 2015) in order to cover a wide range of outdoor wind conditions.

The design of the test facility was almost completely symmetrical, except for the placement of the (closed) doors and the central electrical unit (with the wiring, datalogger, soft- and hardware).

\subsection{Data collection and model development methods}

\subsubsection{General approach}

Detailed airflow rate calculations were executed using the method of Van Overbeke et al. [1,30,31]. Data was collected for different experimental setups during periods of variable outside weather conditions. Different input variables were tested for their appropriateness using Artificial Neural Networks (ANN), selected for further processing and used within a linear algorithm to determine the airflow rates. Finally, methods for analysing the results, regression analysis and Bland Altman analysis were described. These methods will be described in more detail in the next paragraphs. All data processing, filtering, ANN and statistical analyses mentioned in this study were performed with the software Matlab ${ }^{\circledR}$ R2013a.

\subsubsection{Reference airflow rate measurements}

Detailed airflow rate measurements were conducted in the test facility, using the method proposed by Van Overbeke et al. Ref. [1] with moving sensors for the side vents and a method with fixed sensors to sample the ridge vent.

Air velocities were measured in the side vents by a moving sensor in each side opening. The spatial variation of the airflow pattern in the side openings was measured by sampling the full surface of the opening, divided in 48 measurement places. Every measuring place was sampled for $10 \times 1$ s before moving to the next sampling place. When all 48 places were sampled, the sensor started a new measuring round. To measure the total airflow rate, ten measuring rounds were repeated. The air velocity per measuring place was calculated by taking the mean of the 10 rounds of $10 \times 1 \mathrm{~s}$. All these measured mean air velocities were used to calculated the airflow rate with formula [4]. The measurement of one unique airflow rate took approximately $1.5 \mathrm{~h}$. The temporal variation of the airflow pattern was minimized because of this averaging over $1.5 \mathrm{~h}$. The temporal variation of velocity at the sampling locations was logged over a semi-continuously by the moving sensors. Furthermore, the meteomast continuously logged the actual wind conditions in order to account for temporal variations over the full length of the measurements. For each repetition of scanning the opening (48 measuring places, each $10 \mathrm{~min}$ approximately), a new sliding mean of the total airflow rates could be calculated. One of the major advantages of the method was that it was able to measure the full airflow rate pattern, so that when bidirectionality occurred, this could be registered in detail.

The velocities in the ridge vent were measured with eight fixed sensors (equally spread over the length; one sensor failed during the measurements). The mean velocities were calculated over the same period, $1.5 \mathrm{~h}$, as the velocities in the openings. For every time a new measuring round started for the sensor in the side opening, a new sliding mean was calculated in the ridge opening.

The principle to calculate the airflow rate was the same for the side and the ridge openings. The partial airflow rates through equal areas $(A p)$ in the window opening are summed to form the total airflow rate $(Q)$ [4]. The partial airflows were obtained by multiplying the locally measured perpendicular air velocity $(|\bar{Y}|)$ by the partial opening area $(A p)$. The airflow rate results of this method were used as reference to compare the airflow rates resulting from the application of the simplified algorithms.

$\boldsymbol{Q}=\sum_{1}^{\boldsymbol{N}}(|\overline{\boldsymbol{Y}}| \times \boldsymbol{A p} \times 3600)$

Where:

$Q=$ mean airflow rate over a period of approximately $1.5 \mathrm{~h}\left(\mathrm{~m}^{3}\right)$ h)

$|\bar{Y}|=$ mean perpendicular air velocity over a period of approximately $1.5 \mathrm{~h}(\mathrm{~m} / \mathrm{s})$

$A p=$ partial opening surface area $\left(\mathrm{m}^{2}\right)$

$N=$ total number of surfaces in de side or ridge vents

\subsubsection{Preliminary data analysis}

Different velocity components were tested to use as input variables to determine the airflow rate. These velocity components were the perpendicular $|\bar{Y}|$ and parallel $|\bar{X}|$ component, the total velocity $|\bar{U}|$ and the velocity vector $\bar{U}$ all measured at the meteomast. Because an ultrasonic 2D anemometer was used, the $|\bar{X}|$-, $|\bar{Y}|$-component and $\bar{U}$ were immediately available, the $|\bar{U}|$ was derived from the measurements. Previous research showed that models for airflow rates with uni-directional flows gave less accurate results when applied for bi-directional flows [9,13]. For this reason, the data was split in a group where bi-directional $Q_{b i}$ and a group where only uni-directional flows $Q_{u n i}$ occurred. The flow pattern of the data set was categorized as bi-directional when at least one normal velocity component in the side opening had a different sign (opposite direction) compared to the other respective normal components. To rule out the effect of variations or short term fluctuations in the opening, only the mean velocity and not the separate measurements were taken into account to evaluate the bi-directionality in the openings.

Before applying a simple mathematical algorithm, Artificial Neural Networks (ANN) were used to extract or identify the most promising input variables. ANN are information processing systems that can 'learn' a relationship between input and output variables 
by studying given data [32]. Through a process of 'learning' ANN are able to perform useful computations. ANN already proved to be efficient for assessing natural ventilation [33]. The most common model used for function fitting problems is the feedforward model [32] which was used within this research. This model placed the neurons in several layers. The first and last layers represent input and output, respectively. The output layer gives the results that are evaluated by the network. For every input variable, 8 different networks were tested. These networks differed from each other by different properties of the learning rate, the amount of neurons or the momentum rate.

The different input variables of the wind velocities $|\bar{U}|,|\bar{Y}|,|\bar{U}|$ and $\bar{U}$ were used as inputs for the network. The reference airflow rates of the stable, obtained using the method of Van Overbeke et al. Ref. [1] and calculated with formula 4, were introduced as targets for the model. The evaluation of the network results were based on $\mathrm{R}^{2}$-values. ANN were only used to establish whether a strong correlation existed between the input variables and the airflow rates and to make a further selection of potential estimators of the airflow rates.

\subsubsection{Simple mathematical algorithms}

After testing the correlations with ANN, (multiple) linear regression modelling was applied to find fast and simple algorithms to assess the airflow rates for uni- and bi-directional flows. The airflow rate was used as dependent variable and the candidate input variables as independent variables. Simple linear regression [5] was applied to assess the airflow rate with respective input variables $|\bar{U}|,|\bar{Y}|$ and $|\bar{X}|$. Multiple linear regression [6] was used when $\bar{U}$ was implemented.

$$
\begin{aligned}
& \boldsymbol{Q}(\boldsymbol{x})=\boldsymbol{p}_{1} \times \boldsymbol{x}_{1}+\boldsymbol{c} \\
& \begin{array}{l}
\boldsymbol{Q}(\boldsymbol{x})=\boldsymbol{p}_{1} \times \boldsymbol{x}_{1}+\boldsymbol{p}_{2} \times \boldsymbol{x}_{2}+\boldsymbol{c} \\
\text { where: } \\
\qquad p_{1,2}=\text { constants }\left(\mathrm{m}^{2}\right) \\
x_{1,2}=\text { input variables }(\mathrm{m} / \mathrm{s}) \\
\quad c=\text { constant }\left(\mathrm{m}^{3} / \mathrm{s}\right)
\end{array}
\end{aligned}
$$

The agreement between the modelled and the reference data was assessed using regression parameters and Bland Altman analysis. Because the experiments were performed under almost isothermal conditions (no extra heat was added), the assumption was made that no ventilation would occur with absence of wind (measured on the meteomast). Therefore the intercept of the models was set to zero. The accuracy of the linear regression models was tested with two different methods: (1) the coefficient of determination and the regression coefficient; (2) the Bland Altman method [34], with which the respective absolute differences between the modelled and experimental results are related to the average of the modelled and reference results. The agreement between model results and experimental results is analyzed with the slope $\beta_{0}$ and the intercept $\beta_{1}$ (see formula [7]). Ideal models will result in coefficients close to zero.

$$
(\boldsymbol{M R}-\boldsymbol{R R})=\beta_{0} \times \frac{M \boldsymbol{R}+\boldsymbol{R} \boldsymbol{R}}{2}+\beta_{1}
$$

Where:

$M R-R R=$ difference between the modelled results $(\mathrm{MR})$ and the reference results $(\mathrm{RR})\left(\mathrm{m}^{3} / \mathrm{h}\right)$

$\frac{M R+R R}{2}=$ average of the modelled results and the reference results $\beta_{0}=$ coefficient of performance (dimensionless)

$\beta_{1}=$ intercept $\left(\mathrm{m}^{3} / \mathrm{h}\right)$

\section{Results}

\subsection{Experimental data}

The measured airflow rates were split into 2 groups based on the uni- or bi-directional character of the flows. In total, $5953 Q_{u n i}$ and $1477 Q_{b i}$ mean sliding airflow rates were calculated. An example of a bi-directional flow in a side vent $A$ is presented in Fig. 3. In this case, Vent A served as the main inlet opening, with part of the opening functioning as an outlet. The separation between the opposite wind direction zone appeared vertical in the cases of bidirectional flows formed due to the wind (not to be confused with bi-directional flows formed by the stack-effect).

The $Q_{u n i}$ values ranged between of $1612 \mathrm{~m}^{3} / \mathrm{h}$ and $36546 \mathrm{~m}^{3} / \mathrm{h}$, as the $Q_{b i}$ values varied between $1455 \mathrm{~m}^{3} / \mathrm{h}$ and $26792 \mathrm{~m}^{3} / \mathrm{h}$. The magnitude of the airflow rates are influenced only by the outside weather conditions as temperature, wind direction and wind velocity. The wind roses and wind distribution profiles obtained from the data from the meteomast during the measurements are presented in Figs. 4 and 5 respectively. The mean and standard deviation of the incidence angles of the airflow rates $Q_{u n i}$ and $Q_{b i}$ were respectively $(66 \pm 15)^{\circ}$ and $(33 \pm 18)^{\circ}$. As seen in Fig. 5, distinction between uni-directional and bi-directional flows was found to depend mainly on the wind direction, but the results were not strictly linked to specific wind directions as both flow groups occurred at cross covering ranges of wind direction. Overall, the $Q_{u n i}$ occurred for wind directions between (272 and 83) $)^{\circ}$ and (93 and 264$)^{\circ}, Q_{b i}$ occurred for wind directions between (4 and 157) ${ }^{\circ}$ and $(201 \text { and } 355)^{\circ}$. It was seen that the airflow rates with unidirectional flows not only occurred as expected for winds normal or diagonal to the opening and the airflow rates with bi-directional flows occurred not only for side winds. The unexpected results, as normal wind that produced a bi-directional flow, were mainly caused in circumstances of low wind velocities and probably in non-perfect isothermal conditions.

\subsection{Assessing the airflow rate for unidirectional flows in the side vents}

\subsubsection{Preliminary data analysis with ANN}

The data of the airflow rates with uni-directional flows in the side vents were applied to ANN. The input variables $|\bar{U}|,|\bar{Y}|,|\bar{X}|$ and $\bar{U}$ measured on the meteomast were used as input, the airflow rates as output. Table 1 shows the mean $\mathrm{R}^{2}$-values and their standard deviations of the relation between the reference $Q$ and the results of the ANN with different configurations. The $\mathrm{R}^{2}$-values for the total velocity $|\bar{U}|$, perpendicular velocity $|\bar{Y}|$, and velocity vector $\bar{U}$ gave very high results above $98 \%$. The standard deviation between the 8 different ANN's were very small so there was no need to look for the best configuration of ANN as these three input variables all resulted in good correlations. The parallel velocity component $|\bar{X}|$ gave lower $\mathrm{R}^{2}$-values compared to the other input variables, therefore this component was left out for further processing.

\subsubsection{Modelling and analysis of simple airflow rate algorithms}

Tables 2 and 3 present model parameters and the analysis results from the linear curve fitting of the candidate input variables for the $Q_{u n i}$. The parameters showed that the coefficient for input variable $|\bar{Y}|$ stayed approximately the same for models with inputs variables $|\bar{Y}|$ and $\bar{U}$. The results for the regression analysis showed that the $|\bar{U}|,|\bar{Y}|$ and $\bar{U}$ input variables yielded good linear correlations with the airflow rate data for uni-directional flows. However, 


\begin{tabular}{|c|c|c|c|c|c|c|c|c|c|c|c|}
\hline 1.87 & 1.30 & 1.27 & 1.12 & 0.98 & 0.90 & 1.19 & 1.11 & 1.07 & 0.90 & 0.18 & -0.07 \\
\hline 2.09 & 1.96 & 1.83 & 1.60 & 1.50 & 1.54 & 1.57 & 1.66 & 1.57 & 1.11 & 0.27 & -0.10 \\
\hline & 1.82 & 1.89 & 1.78 & 1.74 & 1.72 & 1.79 & 1.68 & 1.34 & 0.84 & 0.14 & -0.09 \\
\hline & 1.61 & 1.48 & 1.29 & 1.50 & 1.42 & 1.48 & 1.53 & 1.29 & 0.86 & 0.04 & -0.10 \\
\hline
\end{tabular}

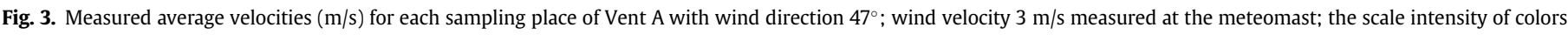
(hot to cold) is related to the magnitude of the velocity.

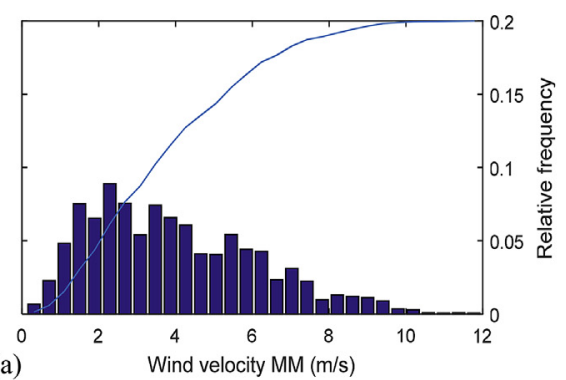

(a)

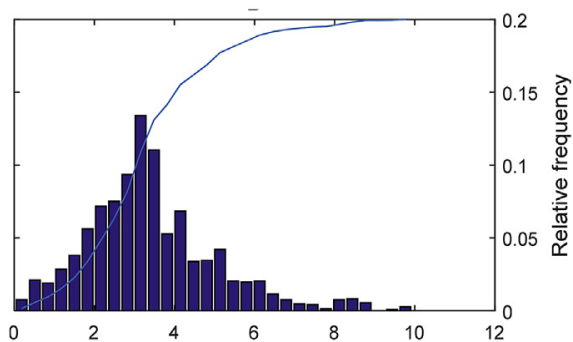

(b)

Wind velocity MM (m/s)

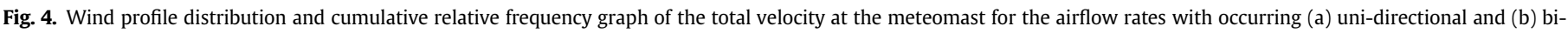
directional flows.

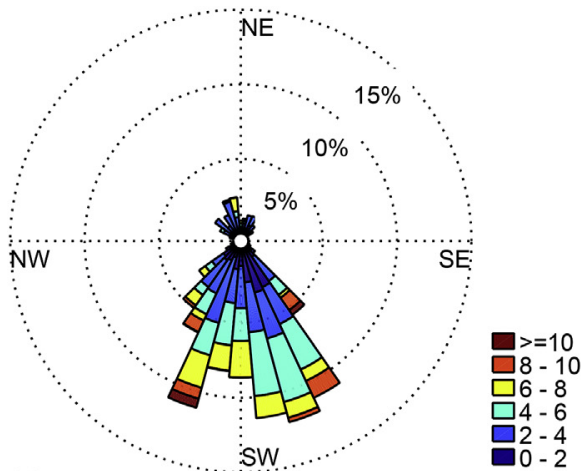

(a)

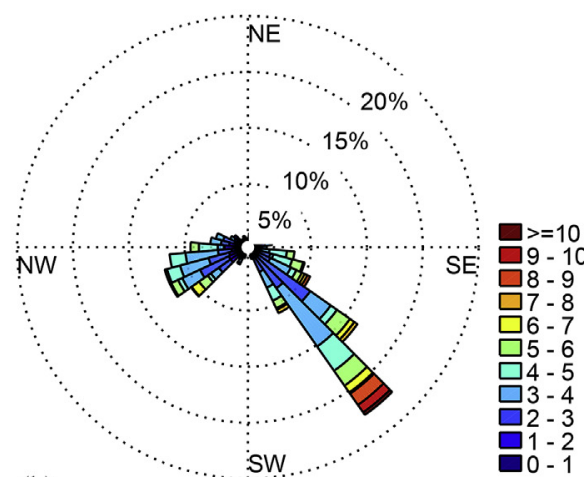

(b)

Fig. 5. Wind rose with data of airflow rates with (a) uni-directional flows series and (b) bi-directional flows series in the side openings of the test facility.

Table 1

Mean and SD of the $\mathrm{R}^{2}$-values for the measured and modelled data for different input variables (\%).

\begin{tabular}{lll}
\hline Input & Mean & SD \\
\hline$|\bar{U}|$ & 98.12 & 0.15 \\
$|\bar{Y}|$ & 98.28 & 0.07 \\
$|\bar{X}|$ & 55.49 & 4.63 \\
$\bar{U}$ & 99.40 & 0.08 \\
\hline
\end{tabular}

\section{Table 2}

Model parameters of the airflow rate related to an input variable: coefficient of variable $\left(\mathrm{p}_{1,2}\right)$ and constant $(\mathrm{c})$; regression analysis results for the modelled and measured total $Q_{u n i}$ : slope (a), intercept $\left(\mathrm{m}^{3} / \mathrm{h}\right)(\mathrm{b})$ and coefficient of determination $\left(\mathrm{R}^{2}\right)$.

\begin{tabular}{lllllll}
\hline Input & $p_{1}$ & $c$ & $p_{2}$ & $\mathrm{a}$ & $\mathrm{b}$ & $\mathrm{R}^{2}$ \\
\hline$|\bar{U}|$ & 3267 & 0 & - & 0.92 & 1234 & 0.96 \\
$|\bar{Y}|$ & 3588 & 0 & - & 0.95 & 673 & 0.96 \\
$\bar{U}$ & $3346(|\bar{Y}|)$ & 0 & $653(|\bar{X}|)$ & 0.94 & 866 & 0.97 \\
\hline
\end{tabular}

the Bland-Altman analysis showed that the $|\bar{Y}|$ - and $\bar{U}$-models had slightly better results than the total velocity $|\bar{U}|$. The $|\bar{Y}|$ component appeared to be the most important contributor in the correlation because the results for the $|\bar{Y}|$-model, with only the perpendicular velocity component as input variable, were comparable to $\bar{U}$. The results with the $|\bar{Y}|$ and $\bar{U}$-input variables lay in the same range, with the latter slightly higher for the regression correlation and lower for the Bland Altman correlation. The graphs (Fig. 6) confirm the good agreements for the reference and modelled airflow rates. Only small differences can be seen between the graphs, depending on the different input variables used. A possible explanation was that all graphs included modelled data with $|\bar{Y}|$-velocity component as input as $|\bar{U}|,|\bar{Y}|$ and $\bar{U}$. Because this data concerned unidirectional flows, the $|\bar{Y}|$-velocity component (perpendicular) was mostly larger than the $|\bar{X}|$-component (parallel) and on top of this, combined with a lower regression coefficient for $|\bar{X}|$.

The graphs show a deviation for the data to the regression line for low values. Even though no extra heat was added, it was possible the stack-effect occurred and gave some airflow rate for some situations with a high sun, a clear sky and above all, a low wind speed.

All three proposed models could identify the true airflow values consistently and had good estimation performances, with $|\bar{Y}|$ and $\bar{U}$ as the best input variables for the models. Input variable $|\bar{Y}|$ had 

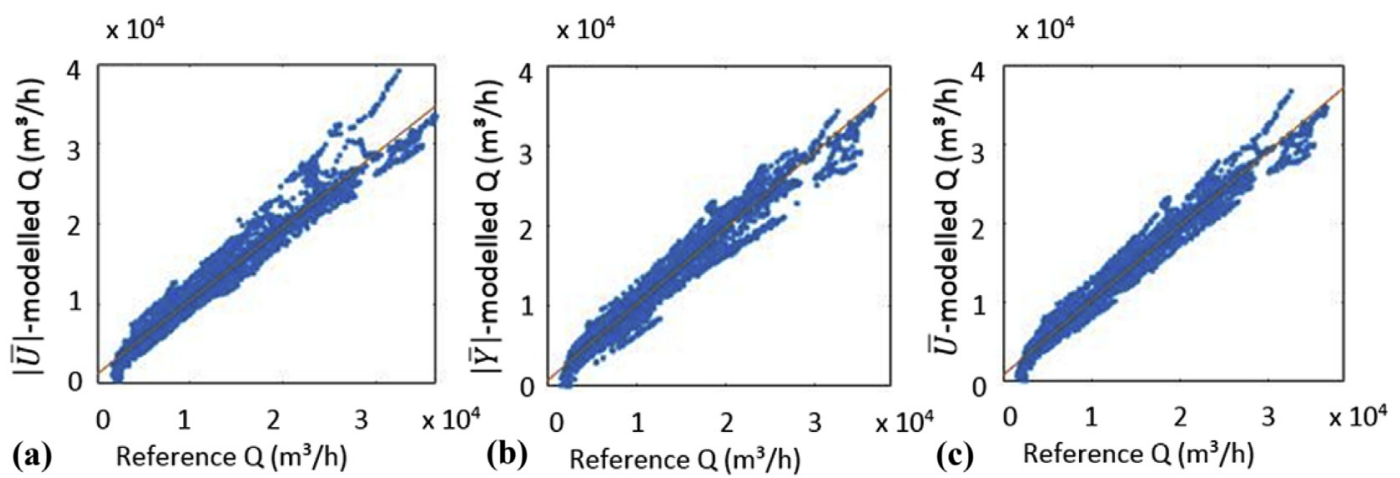

Fig. 6. (Linear) correlation between the reference and the modelled $Q_{u n i}$ for input variables (a) total velocity $|\overline{\boldsymbol{U}}|$; (b) perpendicular velocity $|\overline{\boldsymbol{Y}}|$; (c) velocity vector. $\overline{\boldsymbol{U}}$.

Table 3

Bland Altman results for the comparison of a modelled to measured $Q_{\text {uni }}$.

\begin{tabular}{llr}
\hline Input & $\beta_{0}$ & $\beta_{1}$ \\
\hline$|\bar{U}|$ & 0.07 & -1033 \\
$|\bar{Y}|$ & 0.03 & -457 \\
$\bar{U}$ & 0.05 & -722 \\
\hline
\end{tabular}

preference of choice over components $\bar{U}$ because one component less was needed to obtain similar modelling performance.

\subsubsection{Ventilation opening effectiveness}

Formula [3] which calculates the airflow rate with the opening effectiveness through the inlet opening, proposed by ASHRAE Ref. [24] was applied to the data of the reference airflow rates to determine the $E$-values. Fig. 7 shows a boxplot of the $E$-values calculated for each reference airflow rate. The median $E$ was 0.59 and the 25 - and 75 -percentile were 0.53 and 0.64 respectively. Outliers were found below 0.36 and above 0.78 . Not all outliers were given on the boxplot as some even got up to 6 . The $E$-values plotted against total wind velocity in Fig. 8(b) showed that these outliers were only appearing for low velocities smaller than $1 \mathrm{~m} / \mathrm{s}$, a mathematical artefact. This could be explained because the E's result in very high values when divided by these low wind velocities. For finding any correlation between the $E$ and the incidence angle and the wind velocity, these outliers where separated from the data. A R ${ }^{2}$-value of 0.23 and 0.13 was found for the incidence angle and the wind velocity respectively. The regression coefficients 0.003 and 0.12 showed an increase of $E$ with increasing incidence angle and wind velocity respectively. Fig. 8(a) showed overall lower $E$-values when the wind became more parallel with the opening, in other words, when the incidence angle decreased.

\subsection{Assessing the airflow rate for bidirectional flows in the side vents}

\subsubsection{Preliminary data analysis with ANN}

Table 4 presents mean $\mathrm{R}^{2}$-values and their standard deviations

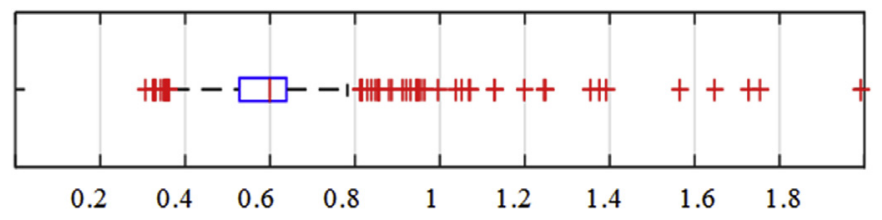

Fig. 7. Boxplot $E$-factor for airflow rates with unidirectional flows. of between the reference $Q_{b i}$ and the results of the different ANN. The input variables $|\bar{Y}|$ and $\bar{U}$ gave highest correlations and therefore showed best potential to find a good fit with $Q_{b i}$. The perpendicular component $|\bar{Y}|$ still showed to be a very important factor to assess the airflow rate, even for bi-directional flows occurring for mainly diagonal and parallel winds. The tangential component was still for this dataset the least good predictor for the airflow rate modelling, but it became a more important determination factor for the airflow rate correlation compared to the results voor $Q_{u n i}$, probably due to the character of the wind (diagonal to parallel). Because of the lower results compared to the other input variables, $|\bar{X}|$ was left out for further processing. The total velocity $|\bar{U}|$ resulted in lower results than found for the unidirectional flows. An explanation could be that the bi-directional flows have larger $|\bar{X}|$ components compared to $|\bar{Y}|$. This can result in a large total velocity, but as seen for the input variable $|\bar{X}|$, it will not necessarily result in a good relation with the airflow rates.

\subsubsection{Modelling and analysis of simple airflow rate algorithms}

Table 5 shows the model parameters and the results of the correlations of the models built for the bi-directional flows. Table 6 gives the results of the Bland Altman analysis. Both input variables $|\bar{U}|$ and $|\overline{\boldsymbol{Y}}|$ applied to the $Q_{b i}$ gave lower results for the regression and Bland Altman correlations as applied to the $Q_{u n i}$. These showed that applying input variable $|\overline{\boldsymbol{Y}}|$ alone gave insufficient information to assess the airflow rate with bi-directional flows. Input variable $\overline{\boldsymbol{U}}$ gave a very good correlation, ANN showed that $|\bar{X}|$ alone was insufficient for assessing the $Q_{b i}$, but gave satisfying results in combination with $|\overline{\boldsymbol{Y}}|(\overline{\boldsymbol{U}})$. The regression and Bland Altman results were high for input variable $\overline{\boldsymbol{U}}$ compared to the other variables. The graphs on Fig. 9 show that the total velocity $|\bar{U}|$ gave the least good correlation for the modelled and reference $Q_{b i}$. The input variable $|\overline{\boldsymbol{Y}}|$ alone improved the results, which could indicate that $|\overline{\boldsymbol{Y}}|$ is more important than $|\overline{\boldsymbol{X}}|$ to assess the ventilation rate. Though the modelling weight of $|\overline{\boldsymbol{X}}|$ is less heavy than the weight of $|\overline{\boldsymbol{Y}}|,|\overline{\boldsymbol{X}}|$ is still of great importance for the accuracy of the model to find the best results for the $Q_{b i}$. These findings can be seen in the model parameters for input variable $\overline{\boldsymbol{U}}$, the coefficient of $|\overline{\boldsymbol{Y}}|$ was more than 3 times higher than the coefficient of $|\bar{X}|$, but was found lower than the coefficient of $|\bar{Y}|$ when only this parameter was used. The models with the best fit, the models with input variable $\overline{\boldsymbol{U}}$, confirmed the importance in differentiation in models for $Q_{b i}$ and $Q_{u n i}$ by a significant lower value of coefficient of $|\overline{\boldsymbol{Y}}|$ for $Q_{b i}$ than for Quni.

\subsubsection{Ventilation opening effectiveness}

Similar to results of the $Q_{u n i}$, the E-values for the $Q_{b i}$ were also calculated. Fig. 10 shows a boxplot of the E-values for $Q_{b i}$. The 

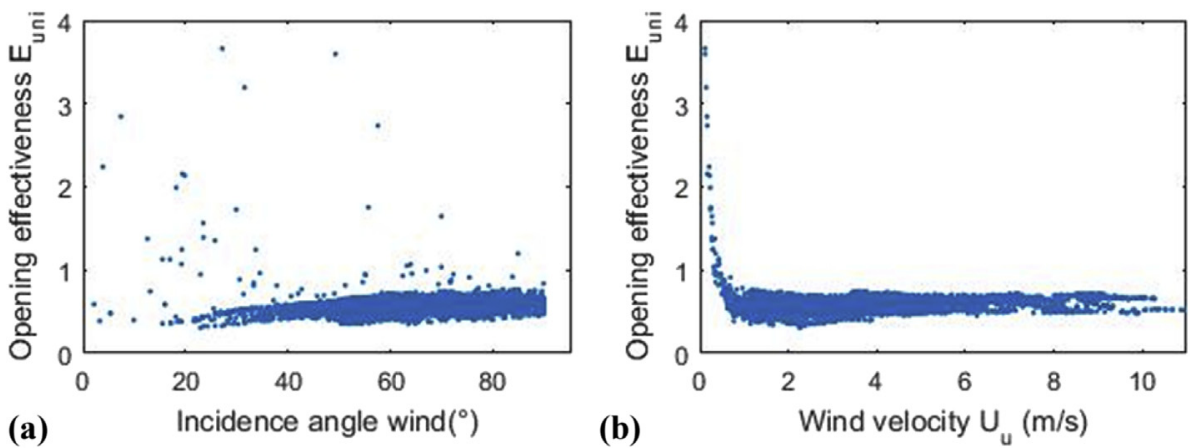

Fig. 8. E-values (opening effectiveness) for $Q_{u n i}$ plotted against the (a) incidence angle of the wind $\left(^{\circ}\right)$ and $(\mathrm{b})$ the wind velocity $(\mathrm{m} / \mathrm{s})$.

Table 4

Mean, standard deviation (SD) of the $\mathrm{R}^{2}$ correlation coefficients (\%) between measured and ANN modelled $Q_{b i}$ for different input variables.

\begin{tabular}{lll}
\hline Input & Mean & SD \\
\hline$|\bar{U}|$ & 88.21 & 1.82 \\
$|\bar{Y}|$ & 96.76 & 0.70 \\
$|\bar{X}|$ & 64.87 & 4.92 \\
$\bar{U}$ & 98.74 & 0.88 \\
\hline
\end{tabular}

Table 5

Model parameters of the airflow rate related to an input variable: coefficient of variable $\left(\mathrm{p}_{1,2}\right)$ and constant $(\mathrm{c})$; regression analysis results between the modelled and measured total $Q_{b \mathrm{i}}$ : slope (a), intercept $\left(\mathrm{m}^{3} / \mathrm{h}\right)(\mathrm{b})$ and coefficient of determination $\left(\mathrm{R}^{2}\right)$.

\begin{tabular}{lllllrl}
\hline Input & $p_{1}$ & $c$ & $p_{2}$ & \multicolumn{1}{l}{$a$} & \multicolumn{1}{l}{$b$} & \multicolumn{1}{l}{$\mathrm{R}^{2}$} \\
\hline$|\bar{U}|$ & 2164 & 0 & - & 0.69 & 2410 & 0.76 \\
$|\bar{Y}|$ & 3597 & 0 & - & 1.10 & -1354 & 0.92 \\
$\bar{U}$ & $2736(|\bar{Y}|)$ & 0 & $808(|\bar{X}|)$ & 0.97 & 174 & 0.96 \\
\hline
\end{tabular}

Table 6

Results of the Bland-Altman analysis for bi-directional airflow rates.

\begin{tabular}{lrr}
\hline Input & $\beta_{0}$ & \multicolumn{1}{c}{$\beta_{1}$} \\
\hline$|\bar{U}|$ & 0.25 & -1988 \\
$|\bar{Y}|$ & -0.14 & 1595 \\
$\bar{U}$ & 0.01 & -29 \\
\hline
\end{tabular}

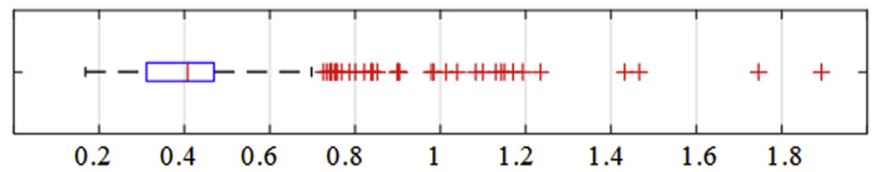

Fig. 10. Boxplot E-factor for airflow rates with bidirectional flows.

velocities (Fig. 11). Similar to the data for the unidirectional flows, the outliers seen in Fig. 9 are appearing only for low wind velocities $(<1 \mathrm{~m} / \mathrm{s})$. Correlations were calculated for the data without these outliers. The E-values increased with increasing incidence angle, a regression coefficient of 0.0051 and $\mathrm{R}^{2}$-value of 0.65 were found for the regression line. No clear relation was found with the total wind velocity measured on the meteomast, the $\mathrm{R}^{2}$-value was found to be small $\left(5 \times 10^{-4}\right)$. The opening effectiveness showed the same behaviour versus the perpendicular and parallel velocity component as seen for the total velocity: small velocity components gave high values and velocity components above approximately $1 \mathrm{~m} / \mathrm{s}$ gave, they did not give extra information to the opening effectiveness.

\section{Discussion}

Easy models to measure naturally ventilated airflow rates are widely available in literature. Chu et al. Ref. [36], Choinière et al. Ref. [37] already found linear correlations between the total velocity and the airflow rates in naturally ventilated greenhouses,

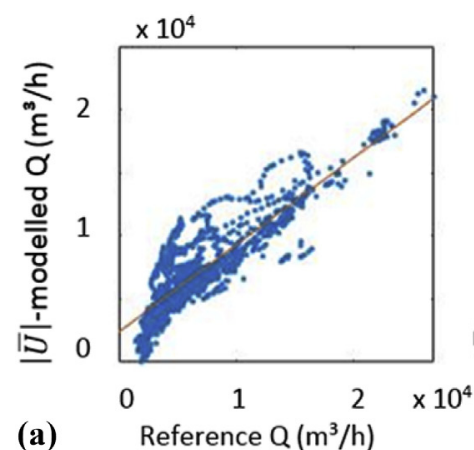

(a)

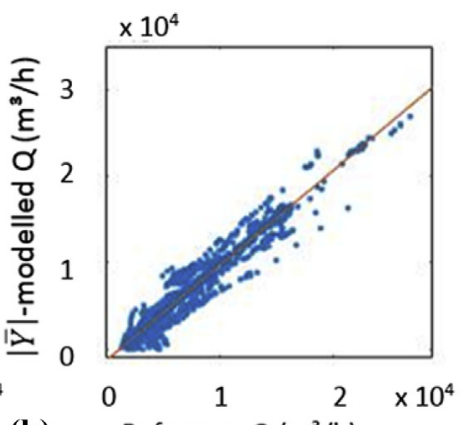

(b)

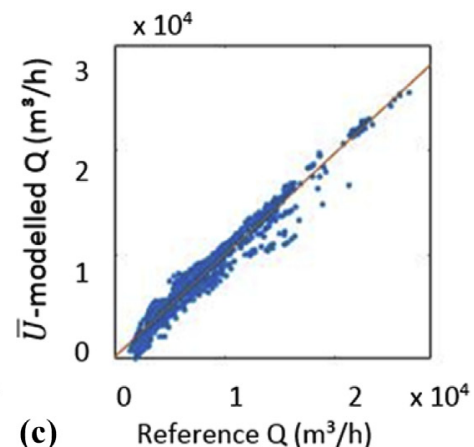

(c) Reference $Q\left(\mathrm{~m}^{3} / \mathrm{h}\right)$

Fig. 9. (Linear) correlation between the reference and the modelled $Q_{b i}$ for input variables (a) total velocity $|\overline{\boldsymbol{U}}|$; (b) perpendicular velocity $|\overline{\boldsymbol{Y}}|$; (c) velocity vector. $\overline{\boldsymbol{U}}$.

median value was 0.41 , the 25 - and 75 -percentile were 0.31 and 0.47 respectively. The outliers were found above 0.70 . Similar to the E-values of the $Q_{u n i}$, high E-values appeared with low wind
Nääs Ref. [17], Verlinde et al. Ref. [39], Yu et al. Ref. [38] in test rooms in wind tunnels, ASHRAE (1981) and Etheridge Ref. [13] for naturally ventilated buildings. Other researchers as Joo et al. 

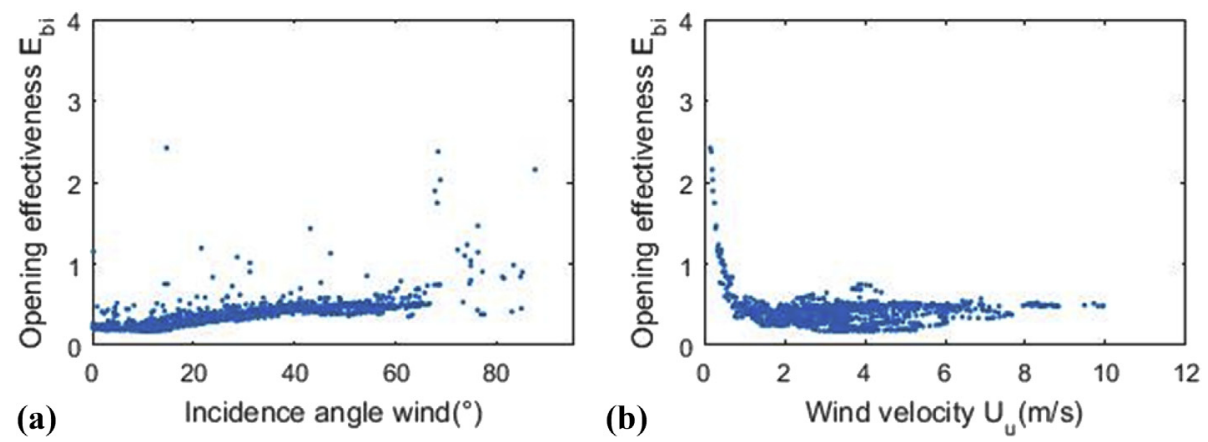

Fig. 11. E-values (opening effectiveness) for $Q_{b i}$ plotted against the (a) incidence angle of the wind $\left(^{\circ}\right)$ and (b) the wind velocity (m/s).

Ref. [26] and Lo et al. (2012) suggested a linear fit between the perpendicular component $|\bar{Y}|$ and velocities in the opening in a large dairy stable and a multi-zone test building respectively.

In this article, the input variables $|\bar{U}|,|\bar{Y}|,|\bar{X}|$ and $\bar{U}$ were tested to find the best input variable in a simple linear model for airflow rate assessment for both uni-directional $\left(Q_{u n i}\right)$ and bi-directional $\left(Q_{b i}\right)$ airflows. For $Q_{u n i}, \bar{U}$ and $|\bar{Y}|$ were found to be the most accurate input variables, where $|\bar{Y}|$ was the most practical input variable because only one velocity component was needed. For 2D or 3D ultrasonic anemometers both the tangential and normal velocity component are available, which makes the input variable $\bar{U}$ most accurate and practical for all wind directions.

In literature mostly it is not clearly specified whether the proposed models can be applied for $Q_{u n i}$ and $Q_{b i}$. Though, if specified, it is mostly stated that these were proposed for $Q_{u n i}$ and when used for $Q_{b i}$, the accuracy will be low [9,13]. No specific models were found in literature for assessing airflow rates based on direct measurements with occurring bi-directional flows caused by the wind effect (not to be confused with models for bi-directional flows due to temperature differences). Our study suggested to use a multiple linear model where the tangential and perpendicular velocity components $(\bar{U})$ are both included.

Though $\bar{U}$ was found to be a good input variable for both $Q_{u n i}$ and $Q_{b i}$, it was not suggested to use the same parameters for both models due to the differences in character of the flow pattern.

$E$ is assumed to be a constant depending on the wind direction, [0.5-0.6] for perpendicular winds and [0.25-0.35] for diagonal winds [24]. The median opening effectiveness of 0.59 for the reference airflow rates was found to lay within these ranges. But values of percentile 75 and above (outliers), lay within the range between 0.64 and 0.78 . One possible explanation for the higher values for $E$ found in this study might be that no obstructions were present in the test facility during measurements. The suggested $E$ value in literature of $0.5-0.6$ are given for practical use in naturally ventilated stables where animals and the arrangement of pen equipment, short partition walls and obstacles inside the buildings can affect the efficiency of the ventilation [29].

In literature, the reference velocity to calculate the opening effectiveness $E$ is the total velocity $|\bar{U}|$. Nääs Ref. [17] and Yu et al. Ref. [38] confirmed the wind angle of incidence is the most important factor influencing opening effectiveness. Our study suggested to use $|\bar{Y}|$ instead of $|\bar{U}|$ within the formula, due to the results where $|\bar{Y}|$ correlated better with $Q_{\text {uni }}$. The suggested values of the opening effectiveness $(E)$ should be checked in another study for it appropriateness with this new parameter.

For $Q_{b i}$, the situation was different. The results of these experiments showed that the perpendicular velocity component had a major influence on the resulting airflow rates, but the tangential component $|\bar{X}|$ had also an important contribution on the airflow rate. This means that applying $|\bar{Y}|$ as suggested for $Q_{b i}$ would give less accurate results because no contrition of the tangential component was present. The use of $|\bar{U}|$ could also lead to less accurate results, because this parameter does not allow for a differentiation in the magnitude of $|\bar{Y}|$ or $|\bar{X}|$. For $Q_{b i}$ it is suggested not to use the formula with the opening effectiveness as $|\bar{U}|$ or $|\bar{Y}|$ are not giving accurate results to assess the airflow rate. In this situation the multiple linear regression with $\bar{U}$ should be used for accurate results.

Further research should focus on commercial animal houses with large openings (dairy stables) to validate the model findings of this study.

\section{Conclusions}

In order to find a fast and simple airflow rate assessment technique for a naturally ventilated test facility, a linear model was applied using velocity measurements on a meteomast of $10 \mathrm{~m}$ height. Different combinations of velocity components were tested to find the most accurate input variable to assess the airflow rate. The total velocity $(|\bar{U}|)$, the perpendicular $(|\bar{Y}|)$ and the tangential velocity component $(|\bar{X}|)$ and the velocity vector $(\bar{U})$ of the air velocity were tested as input variables. The calculated airflow rates were compared to the reference airflow rates measured by the detailed method developed by Van Overbeke et al., Ref. [1].

In addition, the data for modelling the airflow rates was split in uni- and bi-directional flows (opposite directions are present in the airflow pattern of an opening).

For uni-directional flows, $|\bar{Y}|$ and $\bar{U}$ yielded the most accurate airflow rates, though $|\bar{Y}|$ being the easiest input variable because only one velocity component was needed to model the airflow rates. For this reason, it was found to give the best correlation using $|\bar{Y}|$ in ASHRAE's formula of $\mathrm{Q}=\mathrm{E} \times \mathrm{A} \times|\bar{U}|$.

A multiple linear model was suggested for airflow rates with bidirectional flows. The $\bar{U}$ input variable was found to be the best input variable. Though $|\bar{Y}|$ was found to have the most weight within the models. $|\bar{X}|$ was found to be an important contributor too for an accurate estimation of the airflow rate.

\section{Acknowledgements}

This study was conducted in the framework of the Agricultural Research Project IWT090946, which was funded by the Agency for Innovation by Science and Technology (IWT) of the Flemish government. The authors would also like to thank the technicians at ILVO for their advice and support. 


\section{References}

[1] P. Van Overbeke, G. De Vogeleer, E. Brusselman, J.G. Pieters, P. Demeyer, Development of a reference method for airflow rate measurements through rectangular vents towards application in naturally ventilated animal houses: Part 3: application in a test facility in the open, Comput. Electron. Agric. 115 (2015) 97-107, http://dx.doi.org/10.1016/j.compag.2015.05.009.

[2] M. Samer, C. Loebsin, M. Fiedler, C. Ammon, W. Berg, P. Sanftleben, et al., Heat balance and tracer gas technique for airflow rates measurement and gaseous emissions quantification in naturally ventilated livestock buildings, Energy Build. 43 (2011) 3718-3728, http://dx.doi.org/10.1016/j.enbuild.2011.10.008.

[3] S. Calvet, M. Cambra-López, V. Blanes-Vidal, F. Estellés, a. G. Torres, Ventilation rates in mechanically-ventilated commercial poultry buildings in Southern Europe: measurement system development and uncertainty analysis, Biosyst Eng. $106 \quad$ (2010) 423-432, http://dx.doi.org/10.1016 j.biosystemseng.2010.05.006.

[4] L.D. Albright, Environment Control for Animals and Plants, ASABE Textb, ASABE, St. Joseph; MI; U.S.A, 1990.

[5] A. Kiwan, W. Berg, R. Brunsch, S. Özcan, H. Müller, M. Gläser, et al., Tracer gas technique, air velocity measurement and natural ventilation method for estimating ventilation rates through naturally ventilated barns, Agric. Eng. Int. CIGR J. 14 (2012) 22-36.

[6] X. Wang, P.M. Ndegwa, H. Joo, G.M. Neerackal, C.O. Stöckle, H. Liu, et al., Indirect method versus direct method for measuring ventilation rates in naturally ventilated dairy houses, Biosyst. Eng. 144 (2016) 13-25, http:// dx.doi.org/10.1016/j.biosystemseng.2016.01.010.

[7] N.W.M. Ogink, J. Mosquera, S. Calvet, G. Zhang, Methods for measuring gas emissions from naturally ventilated livestock buildings: developments over the last decade and perspectives for improvement, Biosyst. Eng. 116 (2013) 297-308, http://dx.doi.org/10.1016/j.biosystemseng.2012.10.005.

[8] R.S. Gates, K.D. Casey, R.T. Burns, Building emissions uncertainty estimates, Agric. Biosyst. Eng. 52 (4) (2009) 1345-1351. ISSN 0001-2351.

[9] S. Calvet, R.S. Gates, G. Zhang, F. Estellés, N.W.M. Ogink, S. Pedersen, et al., Measuring gas emissions from livestock buildings: a review on uncertainty analysis and error sources, Biosyst. Eng. 116 (2013) 221-231, http:/ dx.doi.org/10.1016/j.biosystemseng.2012.11.004.

[10] S.E. Özcan, E. Vranken, D. Berckmans, Measuring ventilation rate through naturally ventilated air openings by introducing heat flux, Build. Environ. 44 (2009) 27-33, http://dx.doi.org/10.1016/j.buildenv.2008.01.011.

[11] H. Takai, T. Banhazi, Special issue on emissions from naturally ventilated livestock buildings, Biosyst. Eng. 116 (2013) 213, http://dx.doi.org/10.1016 j.biosystemseng.2013.08.006.

[12] C.-R. Chu, Y.-W. Wang, The loss factors of building openings for wind-driven ventilation, Build. Environ. 45 (2010) 2273-2279, http://dx.doi.org/10.1016/ j.buildenv.2010.04.010.

[13] D. Etheridge, Natural Ventilation of Buildings, John Wiley Sons, 2012.

[14] P. Karava, T. Stathopoulos, A.K. Athienitis, Airflow assessment in crossventilated buildings with operable façade elements, Build. Environ. 46 (2011) 266-279, http://dx.doi.org/10.1016/j.buildenv.2010.07.022.

[15] P. Karava, T. Stathopoulos, A.K. Athienitis, Wind driven flow through openings - a review of discharge coefficients, Int. J. Vent. 3 (2004). ISSN 31473-331.

[16] P. Heiselberg, Y. Li, A. Andersen, M. Bjerre, Z. Chen, Experimental and CFD evidence of multiple solutions in a naturally ventilated building, Indoor Air 14 (2004) 43-54, http://dx.doi.org/10.1046/j.1600-0668.2003.00209.x.

[17] F.B.F.I.A. Nääs, D.J. Moura, R.A. Bucklin, An Algorithm for Determinging Opening Effectiveness in Natural Ventilation by Wind, 1988.

[18] P. Heiselberg, Modelling of Natural and Hybrid Ventilation, DCE Lecture Notes No. 004, Aalborg University - Department of Civil Engineering -Indoor Environmental Engineering, 2006. ISSN 1901-7286.

[19] S. Cui, M. Cohen, P. Stabat, D. Marchio, CO2 tracer gas concentration decay method for measuring air change rate, Build. Environ. 84 (2015) 162-169, http://dx.doi.org/10.1016/j.buildenv.2014.11.007.

[20] M. Samer, C. Ammon, C. Loebsin, M. Fiedler, W. Berg, P. Sanftleben, et al.
Moisture balance and tracer gas technique for ventilation rates measurement and greenhouse gases and ammonia emissions quantification in naturally ventilated buildings, Build. Environ. 50 (2012) 10-20, http://dx.doi.org/ 10.1016/j.buildenv.2011.10.008.

[21] C.Y. Chao, M. Wan, A.K. Law, Ventilation performance measurement using constant concentration dosing strategy, Build. Environ. 39 (2004) 1277-1288, http://dx.doi.org/10.1016/j.buildenv.2004.03.012.

[22] A. Belleri, R. Lollini, S.M. Dutton, Natural ventilation design: an analysis of predicted and measured performance, Build. Environ. 81 (2014) 123-138, http://dx.doi.org/10.1016/j.buildenv.2014.06.009.

[23] T.G.M. Demmers, L.R. Burgess, V.R. Phillips, J.A. Clark, C.M. Wathes, Assessment of techniques for measuring the ventilation rate, using an experimental building section, J. Agric. Eng. Res. 76 (2000) 71-81, http://dx.doi.org/ 10.1006/jaer.2000.0532.

[24] I. American Society of Heating, Refrigerating and Air-conditioning Engineers, ASHRAE Fundamentals, 2009.

[25] J. Campen, G.P. Bot, Determination of greenhouse-specific aspects of ventilation using three-dimensional computational fluid dynamics, Biosyst. Eng. 84 (2003) 69-77, http://dx.doi.org/10.1016/S1537-5110(02)00221-0.

[26] H.S. Joo, P.M. Ndegwa, A.J. Heber, B.W. Bogan, J.-Q. Ni, E.L. Cortus, et al., A direct method of measuring gaseous emissions from naturally ventilated dairy barns, Atmos. Environ. 86 (2014) 176-186, http://dx.doi.org/10.1016/ j.atmosenv.2013.12.030.

[27] L.J. Lo, A. Novoselac, Cross ventilation with small openings: measurements in a multi-zone test building, Build. Environ. 57 (2012) 377-386, http:// dx.doi.org/10.1016/j.buildenv.2012.06.009.

[28] T. Boulard, J.F. Meneses, M. Mermier, G. Papadakis, The mechanisms involved in the natural ventilation of greenhouses, Agric. For. Meteorol 79 (1996) 61-77, http://dx.doi.org/10.1016/0168-1923(95)02266-X.

[29] C.-R. Chu, B.-F. Chiang, Wind-driven cross ventilation in long buildings, Build. Environ. $80 \quad$ (2014) 150-158, http://dx.doi.org/10.1016/ j.buildenv.2014.05.017.

[30] P. Van Overbeke, J.G. Pieters, G. De Vogeleer, P. Demeyer, Development of a reference method for airflow rate measurements through rectangular vents towards application in naturally ventilated animal houses: Part 1: manual 2D approach, Comput. Electron. Agric. 106 (2014) 31-41, http://dx.doi.org/ 10.1016/j.compag.2014.05.005.

[31] P. Van Overbeke, G. De Vogeleer, J.G. Pieters, P. Demeyer, Development of a reference method for airflow rate measurements through rectangular vents towards application in naturally ventilated animal houses: Part 2: automated 3D approach, Comput. Electron. Agric. 106 (2014) 20-30, http://dx.doi.org/ 10.1016/j.compag.2014.05.004.

[32] Simon Haykin, Neural networks: a comprehensive foundation, Knowl. Eng. Rev. 13 (2005) 409-412, http://dx.doi.org/10.1017/S0269888998214044.

[33] G.A. Faggianelli, A. Brun, E. Wurtz, M. Muselli, Assessment of different airflow modelling approaches on a naturally ventilated Mediterranean building, Energy Build. (2015), http://dx.doi.org/10.1016/j.enbuild.2015.08.038.

[34] J.M. Bland, D.G. Altman, Statistical methods for assessing agreement between two methods of clinical measurement, Int. J. Nurs. Stud. 47 (2010) 931-936, http://dx.doi.org/10.1016/j.ijnurstu.2009.10.001.

[36] C.-R. Chu, Y.-H. Chiu, Y.-T. Tsai, S.-L. Wu, Wind-driven natural ventilation for buildings with two openings on the same external wall, Energy Build. 108 (2015) 365-372, http://dx.doi.org/10.1016/j.enbuild.2015.09.041.

[37] Y. Choinière, H. Tanaka, J.A. Munroe, A. Suchorski-Tremblay, Prediction of wind-induced ventilation for livestock housing, J. Wind Eng. Ind. Aerodyn. 44 (1992) 2563-2574, http://dx.doi.org/10.1016/0167-6105(92)90048-F.

[38] H. Yu, C.-H. Hou, C.-M. Liao, Scale model analysis of opening effectiveness for wind-induced natural ventilation openings, Biosyst. Eng. 82 (2002) 199-207, http://dx.doi.org/10.1006/bioe.2002.0072.

[39] W. Verlinde, D. Gabriels, J.P.A. Christiaens, Ventilation coefficient for windinduced natural ventilation in cattle buildings: a scale model study in a wind tunnel, Trans. ASAE 41 (1998) 783-788. 